\title{
Simulating the Relationship Between the Hidden Economy and the Tax Level and Tax Mix in New Zealand ${ }^{*}$
}

Patrick J. Caragata

$\boldsymbol{\&}$

David E. A. Giles

Revised, June 1998

\begin{abstract}
In this paper we consider a simple Logistic relationship between the relative size of the Hidden Economy in New Zealand, and the effective tax rates for the major tax components. The model that we estimate from annual time-series data is used to simulate the effects of changes in both the overall tax "burden", and in the tax "mix", on the size of the Hidden Economy as a percentage of measured GDP in that country. At recent taxation levels, we find that for every percentage point reduction in the tax/GDP ratio, the Hidden Economy/GDP ratio drops by about 0.2 percentage points. We also find that the latter ratio is very responsive to changes in the tax "mix" in favour of relatively more indirect taxation; and that at an effective tax rate of about $21 \%$ of GDP, the impact of tax changes on underground activity begins to decelerate. The latter results suggests a tax evasion-efficient frontier for the tax/GDP ratio in New Zealand.
\end{abstract}




\section{Introduction:}

This paper considers the relative size of the Hidden Economy in New Zealand, over the period 1968 to 1994 , and examines the impact of changes in both the aggegate tax "burden", and in the tax "mix" (direct versus indirect, and personal, corporate and indirect tax as a share of total revenue), on underground economic actvity in that country. Internationally, there has been a revival of interest (e.g., Rahman (1992), Caragata (1995), Schneider (1997), and the references cited by Giles (1997d)) in empirical analyses of the Hidden Economy. Hidden economic activity in the form of tax evasion poses a serious threat for the effectiveness of both fiscal and monetary policy, as well as for respect for government and the law. In addition, evaded tax represents a deadweight loss on the economy, and it distorts taxation equity by shifting the taxation burden towards honest firms and individuals. This can result in a stifling of economic growth and employment.

The specific purpose of this paper is to develop and estimate a simple model of the relationship between the size of the Hidden Economy $(\mathrm{H})$ and the major components of taxation revenue $(\mathrm{T})$ in New Zealand. We use data for the historical time-path of the Hidden Economy generated from the latent variables model of Giles (1997d), and analysed by Giles (1997a,b,c). A related study reported by Giles and Caragata (1998) estimates several non-linear relationships between the ratio of Hidden to Measured GDP (H/GDP) and the ratio of Total Tax Revenue to GDP (T/GDP), with an allowance for cyclical growth in real output. They favour a Logistic functional form, and find that there is a "natural rate of underground activity" (i.e., the rate that prevails even with a zero tax burden) of the 
order of $4.4 \%$ of measured (real) GDP; and that the underground activity rate would rise to a minimum of $34.4 \%$ of measured GDP if total tax revenue equalled GDP in nominal terms.

We develop a more sophisticated and refined variant of that model in this paper. In particular, we distinguish between the major components of total tax revenue - namely, personal, indirect, corporate and "other" taxes, and allow for the separate effects of each of these components (as a percentage of GDP) on the Hidden Economy ratio. This allows us to explore the implications, for the relative size of the Hidden Economy in New Zealand, of altering either, or both, the overall level of the tax burden and the tax mix.

The next section discusses some features of the data that are used in this study, including issues relating to data non-stationarity. Section 3 describes the formulation of our disaggregated Logistic model, and the way in which we make it consistent with the aggregate formulation of Giles and Caragata (1998). The econometric estimation and testing results are discussed in section 4, and section 5 is devoted to a number of illustrative policy simulations. The latter provide details about the response of the Hidden Economy to a range of changes in the magnitude and form of the tax-take. Section 6 discusses one particularly interesting policy simulation that relates to the various changes to the New Zealand tax system that took place when the Goods and Services Tax (GST) was introduced in 1986. Some tentative results relating to an efficient frontier for the tax/GDP ratio relative to the Hidden Economy are provided in section 7; and some concluding comments and recommendations appear in section 8 . 


\section{Data Issues:}

Annual data for the (H/GDP) variable are available directly for the period 1968 to 1994 from the results of Giles (1997d). The nominal GDP variable includes an allowance for stock valuation adjustment, and the data are also taken from Colgate (1991). Matching data for 1991-1994 have been obtained from the Budget documents. We also use data for real (1982-83) Gross Domestic Product (GDPR), as in Giles (1997d). The annual data for Total Tax Revenue (T), Personal Tax (TP), Corporate Tax (TC), Indirect Taxes (TI) and Other Taxes (TO) are on a Budget (rather than Inland Revene Department) basis, and are obtained from Colgate (1991), with post-1990 data having being compiled by the New Zealand Inland Revenue Department and New Zealand Treasury. Taxes paid by non-residents and absentees are included in TC, and TP includes Social Security tax in 1968 and 1969 (the last years that this tax was imposed and gathered separately). "Other Taxes" are essentially "taxes on immovable property", and include gift duties, death duties and land tax. The data for (H/GDP) and for (T/GDP) are plotted in Figure 1. Figure 2 shows the four tax components as proportions of GDP, and Figure 3 shows the corresponding "tax shares" over the sample period. All of the basic data are measured in millions of (New Zealand) dollars.

Given that we are working with macroeconomic time-series data, the issues of data stationarity and cointegration are important because they have implications for the appropriate form in which the data should be used when estimating any regression relationships. Giles and Caragata (1998) report 
results which indicate that the rate of growth in GDPR is a stationary series, while (H/GDP) and (T/GDP) are both I(1) but cointegrated. Note that the latter result implies that there exists a unique parameter $\theta$, such that $[(\mathrm{H} / \mathrm{GDP})-\theta(\mathrm{T} / \mathrm{GDP})]=\mathrm{Y}$, where the series $\mathrm{Y}$ is $\mathrm{I}(0)$, or stationary.

Now, breaking Total Tax Revenue into its components, the presence of cointegration at the aggregate level implies that $[(\mathrm{H} / \mathrm{GDP})-\theta(\mathrm{TP} / \mathrm{GDP})-\theta$ (TI/GDP) $-\theta(\mathrm{TC} / \mathrm{GDP})-\theta(\mathrm{TO} / \mathrm{GDP})\}]=\mathrm{Y}$, and so there exists at least one linear combination of (H/GDP) and the individual tax ratios which is stationary. This stationarity is indeed associated with cointegration between the five variables concerned, as some basic Dickey-Fuller unit root tests indicate that each of the individual tax rates are $\mathrm{I}(1)$. Given that we now have more than two $\mathrm{I}(1)$ variables under consideration the nature of this cointegration, in terms of the number of cointegrating vectors, could be explored further by means of the Maximum Likelihood methodology of Johansen and Juselius (1990), but this is not directly

relevant to the present study. However, the presence of cointegration implies that although certain of the series that we will be using in the model below are I(1), all of the data can be used without any prior differencing.

\section{Model Formulation:}

Following the aggregative results in Giles and Caragata (1998), we have adopted a Logistic function to represent the relationship between (H/GDP) and the components of (T/GDP). The rate of growth in real (measured) GDP is also incorporated into the model's specification. It is important that the 
estimated relationship based on the disaggregated data is consistent with the earlier aggregate relationship, and so the parameter estimates for this model which are reported in Table 2 of Giles and Caragata (1998) are used to introduce appropriate constraints on the coefficients when the model below is estimated by Maximum Likelihood.

The aggregate Logistic model of Giles and Caragata (1998), referred to above can be written as:

$$
(H / G D P)=1 /[1+\exp \{-((T / G D P)-\alpha) / \beta\}]+\gamma\left(\Delta \text { GDPR/GDPR }_{-1}\right)+\text { error }
$$

The corresponding model with total tax broken down into its four components is of the form:

$$
\begin{gathered}
(\text { H/GDP })=1 /\left[1+\exp \left\{-((\text { TP/GDP })-\alpha) / \beta_{\mathrm{P}}-((\text { TI/GDP })-\alpha) / \beta_{\mathrm{I}}-((\mathrm{TC} / \mathrm{GDP})-\alpha) / \beta_{\mathrm{C}}\right.\right. \\
\left.\left.-((\mathrm{TO} / \mathrm{GDP})-\alpha) / \beta_{0}\right\}\right]+\gamma\left(\Delta \text { GDPR/GDPR }_{-1}\right)+\text { error }
\end{gathered}
$$

Defining

$$
b_{P}=\left(1 / \beta_{P}\right) ; b_{I}=\left(1 / \beta_{I}\right) ; b_{C}=\left(1 / \beta_{C}\right) ; b_{O}=\left(1 / \beta_{0}\right) ; \text { and } b=b_{P}+b_{I}+b_{C}+b_{O} \text {, }
$$

the last model can be written as:

$$
\begin{aligned}
(H / G D P)= & 1 /\left[1+\exp \left\{-b_{P}(T P / G D P)-b_{I}(T I / G D P)-b_{C}(T C / G D P)-b_{O}(T O / G D P)\right.\right. \\
& +\alpha b\}]+\gamma\left(\Delta \text { GDPR/GDPR }_{-1}\right)+\text { error }
\end{aligned}
$$

We then constrain the parameters so that $\alpha=1.2665$ and $b=1 / 0.4117$, these being the point estimates for the corresponding parameters in the aggregate Logistic model reported by Giles and Caragata (1998). This implies, of course that only three of the parameters $b_{P}, b_{I}, b_{C}$ and $b_{O}$ can be estimated freely ${ }^{1}$. When the restricted disaggregated model is estimated by non-linear Maximum Likelihood, the predicted values for the dependent variable will then exactly match those from the estimated aggregate model, without any constraint having to be placed on $\gamma$. 


\section{Estimation Results:}

The SHAZAM (1993) econometrics package was used for all of the econometric analysis in this study, and the results of estimating the above model using a sample from 1969 to 1994 appear in Table 1. In that table, $\mathrm{R}^{2}$ is the squared correlation between the actual and predicted values for the dependent variable; GOF is the Chi Square (with one degree of freedom) statistic for testing the Normality of the errors; and DW is the exact Durbin-Watson statistic as proposed for non-linear models by White (1992). Asymptotic "t-values" appear in parentheses below the parameter estimates. There is no evidence of first-order serial correlation in the residuals, and although the p-value for the Normality test statistic is marginal, this test is only asymptotic and has quite low power in small samples. The overall quality of this estimated model compares very favourably with those of the estimated aggregate models reported in Table 2 of Giles and Caragata (1998).

\section{Some Basic Simulation Results:}

A number of illustrative simulations have been undertaken with the above estimated model to determine the extent to which the (H/GDP) ratio would have been affected historically by changes in the overall tax burden and/or changes in the tax mix. That is, the estimated coefficient values from Table 1 have been used in conjunction with suitably modified tax data to predict the values of the dependent variable of the model, year by year, from 1969 to 1994. 
Table 2 provides some basic comparative results. In that Table, the "control" time-path shows the predicted values of (H/GDP) with all of the data set to their actual historical values - this is the series of predicted values when the model is estimated. The "control" provides a bench-mark time-path against which the other simulation paths should be compared. The policy changes referred to in the rest of Table 2 are as follows:

Policy 1 The total tax burden is unaltered from its historical path, but the tax mix is altered by interchanging the historical values for personal and indirect taxes. (The values of TC and TO are unaltered.)

Policy 2 The tax mix is changed by setting personal taxes to zero in every past period, and increasing indirect taxes to compensate, so that the total tax burden is unaltered in every year. (The values of TC and TO are unaltered.)

Policy 3 The tax mix is unaltered, but the tax burden is halved in each year.

Policy $4 \quad$ As for Policy 1, but the total tax burden is halved as for Policy 3.

Policy $5 \quad$ As for Policy 2, but the total tax burden is halved as for Policy 3.

We see from Table 2 that the policies outlined above are strictly increasingly effective, in terms of reducing the size of the Hidden Economy relative to the measured economy, as we move from Policy 1 through to Policy 5. From Figure 2 we know that personal income taxes were greater than indirect taxes in every year from 1968 to 1994 . For example, personal taxes and indirect taxes accounted for $50.1 \%$ and $36.2 \%$ of total tax revenue, respectively, in 1994 . So, Policy 1 involves a substantial 
decrease in direct taxes (e.g., 28\% in 1994) and an increase in indirect taxes (e.g., 38\% in 1994), but without any change in the aggregate tax burden. It is not surprising, therefore, that the relative size of the Hidden Economy falls in every year under this policy, for example to roughly $9.4 \%$ of measured GDP in 1994, and by an average of $11.2 \%$ (i.e., from $8.96 \%$ to $7.96 \%$ ) over the full sample period. This indicates the powerful effect of indirect taxes with respect to behaviour affecting activity in the Hidden Economy in New Zealand.

The explanation for the tax evasion minimisation potential of indirect taxes is based on the theory of incentive structures and learned behaviour (Giles and Caragata, 1998). The learning curve is an evolutionary depiction of the behavioural consequences of the incentive structure operating in a particular jurisdiction or organisation. Taxes are a current and potential cost of doing business for firms, and a current and potential cost of living for individuals. Just as taxes reduce cash flow for firms, they also reduce disposable income for individuals. As a result, taxes affect the incentive structures of both firms and individuals. Minimising taxes is a true cost savings and both firms and individuals attempt to maximise rewards at minimal cost with respect to their interaction with the tax system. There appear to be more opportunities and less constraints for individuals and firms to minimise income as compared to indirect taxes.

First, income is easier to disguise than a sales transaction because individuals have more control over opportunities to disguise income than over opportunities to disguise purchases, because income is generally from a few sources known personally to the taxpayer, while purchases are generally made 


\section{Taxes and the Hidden Economy}

in stores owned and managed by people with whom the taxpayer has no personal contacts. The transaction costs of organising a network of non-market transactions or organised tax evasion of sales are high as compared to the transaction costs of evading personal income tax (beyond the scope of pay-as-you-earn or income withholding tax at source regimes).

Second, taxpayers are more motivated to protect their income from all incursions such as taxation, because income is a personal possession and a tax on such income is a direct threat to a personal possession. This income is deemed, either explicitly or explicitly, by the taxpayer to be a property right, and is defended accordingly. On the other hand, a tax on a consumption item is a tax on an item owned by someone else, and only becomes a threat if the taxpayer decides to buy the item (as compared to doing without, bartering or stealing, each of which contains costs and risks). Third, because income is a personal possession the risks of getting caught are lower than for a firm which needs to keep audited records of sales and for which "benchmark" or "comparables" firm profiles are available to the tax audit team.

Fourth, the rewards for evading on personal tax are higher than the rewards for evading consumption tax because income is generally larger than purchases. Related to this is the fact that the tax rate on income is higher than on consumption, thus the taxpayer will see that there is more at stake in income tax evasion as compared to sales tax evasion. As a result of these elements of control, possession and reward, the opportunities and constraints favour the choice of income tax evasion as compared to consumption tax evasion. Accrordingly, individuals probably devote more learning time 
to minimising income taxes as compared to indirect taxes, which reinforces their preference for income tax evasion.

Making a simple comparison between just Policies 1 and 2, the latter obviously involves just a "stronger" tax mix change of the above type than does the former policy, For example, under Policy $2,86.3 \%$ of total tax revenue would now be gathered by indirect taxation in 1994 , while the shares of corporate and "other" taxes would be unaltered from their actual values. Accordingly, the relative magnitudes of the Policy 1 and Policy 2 figures in Table 2 are to be anticipated. Moving between Policies 1 and 2, the share of indirect to total tax revenue increases by $72 \%$ in 1994 . This is a little less than double the percentage increase in this share between the "control" and Policy 1. Comparing the sample average values for the shares, that for indirect taxes rises from $29.6 \%$ to $57.3 \%$ between the "control" and Policy 1 (a rise of 94\%), while it rises from 57.3\% to $86.9 \%$ (a rise of 52\%) between Policies 1 and 2. Continuing to use sample averages, we see that in tandem with these changes, the relative size of the Hidden Economy fell by $11.2 \%$ between the "control" and Policy 1 , and by $11.9 \%$ between Policies 1 and 2 . These figures imply average elasticities of approximately 0.12 and -0.23 respectively, again underscoring the potential impact on the Hidden Economy of changes in indirect taxation, even at quite high rates for the latter.

Recalling the definition of Policy 3, given above, we see that it involves a situation in which the tax/GDP ratio is halved (e.g., from $34.5 \%$ to $17.3 \%$ in 1994) uniformly across all tax components. Thus, it is still the case that $50.1 \%$ of tax revenue is in the form of personal tax, $36.2 \%$ is by way of 
indirect taxes, and $13.6 \%$ comes from corporate taxes in 1994, for instance. The result is a shrinkage in the relative size of the Hidden Economy from a ("control") value of approximately $10 \%$ to a value of approximately 7\%, in 1994. That is, at actual 1994 rates, for each percentage point reduction in the aggregate tax burden, the Hidden Economy declines by approximately 0.2 percentage points. The result in 1994 is a simulated (H/GDP) ratio which is close to the actual historical minimum of $6.86 \%$ in 1968, and to the simulated historical minimum of $7.53 \%$ in 1970 . A more extensive discussion of other simulations involving changes to the aggregate tax/GDP ratio in the absence of changes to the tax-mix is given by Giles and Caragata (1998). That discussion also includes alternative interpretations, such as explicit elasticity calculations, of the impact of such tax changes.

Policy 3 is useful here, however, as part of the basis for comparing the effects of changes in the tax burden with those of changes in the tax-mix. Considering Policy 3 alongside Policies 1 and 2, we see if there is a sufficiently large reduction in the overall tax burden, with no change to the tax mix, then this can result in a greater reduction in underground activity than can be achieved by quite dramatic changes to that mix. The details of this last result are explored further, and in more detail, below.

Given the above results, those associated with Policies 4 and 5 are ordered according to our expectations. Considering Policy 4, we see that the simulated figures for (H/GDP) are only slightly less than those associated with Policy 3 and, not surprisingly, thse for Policy 5 are the lowest of those considered in this part of the analysis. 
Table 3 shows the results of more detailed simulations in the spirit of Policy 3, above. There, reductions in the total tax burden ranging from $10 \%$ to $100 \%$ (i.e., no taxes) are considered, year by year, with no change to the tax mix. The results corresponding to a 50\% tax cut in this table are just those shown for Policy 3 in Table 2. In addition, it should be noted that in the case of zero taxes (a $100 \%$ tax cut), the mean figure of $4.67 \%$ over the time-period in question differs slightly from the figure of $4.41 \%$ reported for the Logistic model in Table 3 of Giles and Caragata (1998) when there is no tax burden. This reflects the fact that the rate of growth in real GDP was set to zero in obtaining the latter figure, whereas the actual historical values for this variable are used to generate the simulation paths here, and this growth was positive on average over the sample.

We see that reducing the total tax burden always reduces the (H/GDP) ratio, as is expected from the discussion above, and from the related results of Caragata and Small (1996) and of Giles and Caragata (1998). Comparing the results in Table 3 with that for Policy 1 in Table 2, we also see that a uniform reduction in the tax burden of the order of $10 \%$ is roughly equivalent to altering the tax mix by interchanging the roles of personal and indirect taxes, in terms of the reduction in the relative size of the Hidden Economy. Similarly, a flat reduction of roughly $70 \%$ in all tax components is needed in order to reduce the size of the Hidden Economy to the degree that can be achieved by means of Policy 5 in Table 2.

A corresponding set of results, which provide more detail along the lines of Policy 4 above, are given in Table 4 . In that case, the total tax burden is again reduced by amounts ranging from $10 \%$ to $100 \%$ 
of its original value, and simultaneously the tax mix is adjusted by interchanging the values of TP and TI in each year. The last column in Table 4 is identical to its counterpart in Table 3 , as it should be : if total taxes are zero (a 100\% reduction in the burden), then altering the tax mix is not an issue. Similarly, the results in Table 4 corresponding to a 50\% tax cut are just those for Policy 4 in Table 2. Apart from this last result, the figures in Table 4 are unambiguously smaller than their counterparts in Table 3. This is exactly as would be expected from our discussion above of the results in Table 2.

\section{The Introduction of the Goods and Services Tax:}

Important changes to the taxation system were introduced in New Zealand in October 1986. At that time, sales taxes were abolished and the Goods and Services Tax (GST) was introduced, at an initial rate of $10 \%$ which was subsequently raised to its present rate of $12.5 \%$ in 1989 . Simultaneously, major changes were made to the personal income tax and corporate tax scales, with the effects of simplifying their structure and reducing the extent to which they were regressive. These changes affect the data from 1987 to 1994 .

Table 5 offers some simple results relating to the question: "If the GST had not been introduced, how might this have affected the relative size of the Hidden Economy?" The results in that table allow for two basic situations. First, the revenue due to the GST may have been foregone totally. Second, this foregone GST revenue may have been made up completely via just one of personal, company, 
or other taxes. Clearly, there are also other possibilities, although these are not explored further here. The simulations reported in that table are based on data for TP, TI, TC and TO which differ from the actual historical figures only by an amount equal to the time path for the GST. So, they focus on a partial effect relating to the GST, and the other taxation change noted above are still incorporated into the data and hence into the analysis.

From Table 5 we see that the GST has accounted for approximately $20 \%$ of total tax revenue on average since its inception, for about $25 \%$ of total tax revenue in recent years, and (as can be seen from Figure 3) for the bulk of indirect taxes. So, if the GST had not been introduced and all of this potential revenue had been foregone, we know from the results in Tables 2 - 4 that (H/GDP) would be expected to be lower than for the corresponding "control" values. Of course, under this scenario there is a reduction in total revenue and a change in the tax mix of a form that is not covered in those earlier tables.

The nature of this change to the tax mix is shown in Table 6. Obviously, in the absence of the GST there is a change in the mix in favour of direct (especially personal) taxes, and at the expense of indirect taxes. We know from (the reverse of) Policies 1 and 2 in Table 2, that this alone would induce an increase in (H/GDP). However, with no GST there is a reduction in the overall tax burden of the order of $20 \%$ to $25 \%$, and this alone would lead to a decrease in (H/GDP), as we know from Table 3. This example is useful as it underscores the (possibly opposing) effects arising from changes in the tax burden and changes in the tax mix. In this particular case the burden effect 
outweighs the mix effect, and the net result is a fall in (H/GDP) if the foregone GST revenue is not recovered via some other form of taxation.

On the other hand, suppose that the GST had not been introduced and that the foregone GST revenue had been recovered completely via increased personal and corporate taxes. The last column in Table 5 simulates this situation, with the GST revenue being partitioned, year by year, across personal and corporate taxes according to thier relative shares of total tax revenue. We see that in this case, the relative size of the Hidden Economy would have been greater than in the historical "control". This result also makes intuitive sense. One would anticipate a rise in the Hidden/Measured Economy ratio if the tax burden on personal income increases, because the incentive to evade is stronger when income is under threat. Similarly, in the case of companies, large firms will have a greater incentive to avoid, and smaller firms will be stimulated to evade, if there is a shift from a consumption tax to a tax which more directly targets firms' incomes.

Obviously, all of the simulations which are reported in Tables 2 to 5 are merely illustrative of the many interesting policy issues which can be addressed by using our simple model of the relationship between the relative size of the Hidden Economy and the components of tax revenue. Based on anecdotal evidence, Hotelling (1939, p.152) concluded that excise taxes or taxes on the sale of goods tend to promote more evasion and have a higher collection cost than do personal taxes. Our results for New Zealand run contrary to this conclusion. 


\section{An Efficient Frontier for the Tax/GDP Ratio Relative to the Hidden Economy:}

From the analysis and discussion of the last two sections, it is clear that higher tax burdens, as measured by the tax/GDP ratio, promote an ongoing increase in the size of the Hidden Economy and the tax evasion gap. Conversely, a reduction in the tax/GDP ratio will induce a reduction in the Hidden Economy and the tax evasion gap. At what point do diminishing returns in reducing the Hidden Economy set in as taxes are cut? Or, what level of cut in the tax/GDP ratio combined with a proxy for an efficient tax mix minimises the relative size of the Hidden Economy? At a point where diminishing returns arise, a new unit reduction in the tax rate will yield progressively smaller reductions in the size of the Hidden Economy.

From the analysis earlier we have concluded that the Hidden Economy will shrink if the tax mix emphasizes indirect taxes more heavily than direct taxes. The figures in Table 4 above, which involve a switch of the personal and indirect tax shares, have been used to derive the changes in the (H/GDP) ratio for selected years, and for the average over the full sample period of 1968 to 1994. These data, which appear in Table 7, suggest the following if we are searching for the point at which diminishing returns set in, given this new tax mix, as we progressively simulate a tax cut.

Regardless of which year we consider, we see that the reduction in the relative size of the Hidden Economy first begins to slow down (i.e., there is a "deceleration" effect) when the tax ratio is cut by $20 \%$ from the "control", as opposed to a 10\% cut. In terms of 1994 figures, this means that this 
deceleration occurs at a (T/GDP) ratio of $27.6 \%$, or at a ratio of $24 \%$ in terms of the sample average data. In most years, the next point where a deceleration becomes noticeable when moving from a $30 \%$ cut to a $40 \%$ cut in the tax rate. The latter equates to a resulting (T/GDP) ratio of $18 \%$. If one is cautious and takes the simple average of these two points, the result is a tax/GDP ratio of approximately $21.0 \%$ in terms of the full 1968-1994 data sample. More research will need to be undertaken to refine this estimate. The implications of this result are quite important.

First, this appears to be the first attempt to estimate the efficient frontier in the tax/GDP ratio relative to the objective of reducing the size of the Hidden Economy. Previous work by Scully (1996a, 1996b) indicates that the reduction in the tax/GDP ratio promotes greater economic activity. Our finding confirms that he objective of reducing the size of the Hidden Economy is compatible with promoting economic growth.

Second, shrinking the tax gap broadens the tax base, and ensures that the tax burden is more widely spread. Therefore, reducing the size of the Hidden Economy is a strong, positive contribution to fairness and equity. Third, this optimal frontier for the tax/GDP ratio is roughly in the same range as that discovered by Scully for maximising economic growth (16.5-23.0\%, with an average of $19.7 \%$. Thus, again there is a strong compatibility between the objectives of maximising economic growth and minimising the size of the Hidden Economy. 
These two independent modelling exercises, with different objective functions have reached the same general conclusion about the efficient size of the tax/GDP ratio. The existence of a frontier which maximises efficiency through growth, and also promotes fairness and equity through the reduction of tax evasion and avoidance is an interesting and important finding.

\section{Concluding Comments:}

In this paper we have extended earlier, more aggregative, work by Giles and Caragata (1998) on the relationship between the tax/GDP ratio and the relative size of the Hidden Economy in New Zealand. By breaking down aggregate tax revenue into its major componenst - personal, indirect, corporate, and "other", we have ben able to measure the relative effects, on undergound activity, of altering the tax "mix", as opposed to simply altering the aggregate tax burden.

A simple simulation model has been used to consider a variety of policy scenarios. Among the major conclusions that we can draw from this work are the following. First, our modelling and analysis indicates that although there is a generic difference between the sources of evasion and avoidance, both are quite sensitive to the level of the tax rate (tax/GDP basis) and the tax mix (direct, indirect relative to GDP). Increasing the rate of income tax aggravates, rather than resolves, both avoidance and evasion problems, including the deadweight loss that arises from avoidance and evasion, and misses the fundamental nature of the incentive structure that shapes tax evasion and avoidance decisions by firms and individuals. 
Second, our results show that in terms of recent taxation levels, for each percentage point reduction in the aggregate tax/GDP ratio, the Hidden Economy shrinks in size (relative to measured GDP) by about 0.2 percentage points.

Third, we have found that there is a powerful reaction in the Hidden Economy to changes in the tax mix which favour indirect taxes - such a policy change invokes a marked reduction in the relative size of underground activity in New Zealand.

Fourth, we have shown that if there is a suffuciently large reduction in the overall tax burden, with no change in the tax mix, then there can be larger reductions in underground economic activity than can be achieved even through quite extreme tax-mix changes alone.

Fifth, with respect to the introduction of the Goods and Services Tax (and other associated tax changes) in 1986, we have demonstrated that if that this tax had not been introduced, and the associated revenue had been lost entirely, then the net effect of the associated eduction in the tax burden, together with the corresponding change in the tax mix, would have been a reduction in the Hidden/Measured GDP ratio of the order of one percentage point in an average year. On the other hand, if it had been gathered solely by increased personal and corporate taxes, the relative size of the Hidden Economy would have increased relative to its simulated historical path.

Finally, we have explored the notion of an efficient frontier for the tax/GDP ratio relative to the size 
of the Hidden Economy, and we have determined (tentatively) that it is at an aggregate tax rate of the order of $21 \%$ that the impact of tax changes on underground activity begins to decelerate. Interestingly, and importantly, this accords nicely with Scully's (1996a, 1996b) results for a corresponding frontier for the tax rate and (measured) economic growth in New Zealand.

The research reported in this paper supports Clotfelter's $(1983$, p.373) conclusion that "...tax rates should be considered along with enforcement, tax simplicity, and information reporting as valid instruments for influencing tax evasion". On the other hand, our findings with respect to the link between tax evasion and the preference for using indirect taxes to reduce the size of the tax evasion gap cannot support Gordon and Neilsen's (1996) finding that "Denmark could reduce the real costs of avoidance activity by putting more weight on income rather than value-added taxes".

The policy simulations that we have undertaken are only illustrative, but they provide compelling evidence regarding the importance and the nature of the links between the tax burden and/or tax mix, and the extent of underground economic activity in New Zealand. The model that we have developed and used here can be adopted to simulate other policy scenarios beyond those that we have reported, and it thus provides an important tool to be used together with other empirical methods in our ongoing study of the health of the tax system. 


\section{Footnotes:}

* We are most grateful to Johannah Branson, Judith Giles, Anna Heiler, Gerald Scully and John Small for their many suggestions and constructive comments. Of course, none of these individuals is responsible for our results or conclusions.

1. Of course, the results are invariant to which of the paprameters are estimated freely. 


\section{References:}

Caragata, P. J. (1995), The Integration of the Formal and Informal Financial Sectors in Albania, Mission Report for the International Monetary Fund, Washington, D.C..

Caragata, P. and J. P Small (1996), "Monitoring the Tax Mix, Tax Shocks and Potential Economic Impacts: The PIC Model", Working Paper No. 3 (revised), Working Papers on Monitoring the Health of the Tax System, Inland Revenue Department, Wellington.

Clotfelter, C. T. (1983), "Tax Evasion and Tax Rates: An Analysis of Individual Returns", Review of Economics and Statistics, LXV, 363-373.

Colgate, P. (1991), "Databases for Taxation Modelling: Report to the Inland Revenue Department", New Zealand Institute of Economic Research, Wellington.

Giles, D. E. A. (1997a), "Causality Between the Measured and Underground Economies in New Zealand", Applied Economics Letters, 4, 63-67.

Giles, D. E. A. (1997b), "The Hidden Economy and Tax-Evasion Prosecutions in New Zealand", Applied Economics Letters, 4, 281-285.

Giles, D. E. A. (1997c), Testing for Asymmetry in the Measured and Underground Business Cycles in New Zealand", Economic Record, 72, 225-232.

Giles, D. E. A. (1997d), "The Hidden Economy and the Tax-Gap in New Zealand: A Latent Variable Analysis", Discussion Paper 97-08, Department of Economics, University of Victoria. 
Giles, D. E. A. and P. Caragata (1998), "The Learning Path of the Hidden Economy: The Response to Tax and Growth Effects in New Zealand", Econometrics Working Paper EWP9805, Department of Economics, University of Victoria.

Gordon, R. H. and s. B. Neilsen (1996), "Tax Avoidance and Value-Added vs. Income Taxation in an Open Economy", Working Paper 5527, National Bureau of Economic Research, Cambridge, MA.

Hotelling, H. (1939), "The Relation of Prices to Marginal Costs in an Optimum System", Econometrica, 7, 151-155.

Johansen, S. and K. Juselius (1990), "Maximum Likelihood Estimation and Inference on Cointegration - With Applications to the Demand for Money", Oxford Bulletin of Economics and Statistics, 52, 169-210.

Rahman, A. (1992), "The Informal Financial Sector in Bangladesh : An Appraisal of its Role in Development", Development and Change, 23, 147-168.

Schneider, F. (1997), "Empirical results for the Size of the Shadow Economy of Western European Countries Over Time", Working Paper 9710, Institut für Volkswirtschaftslehre, Linz University. Scully, G. W. (1996a), "Taxation and Economic Growth in New Zealand", Pacific Economic Review, 1, 169-177. (Previously, Working Paper No. 14 (revised), Working Papers on Monitoring the Health of the Tax System, New Zealand Inland Revenue Department, Wellington. Scully, G. W. (1996b), "The Growth-Maximizing Tax Mix in New Zealand", Working Paper No. 20, Working Papers on Monitoring the Health of the Tax System, New Zealand Inland Revenue Department, Wellington. 
Taxes and the Hidden Economy

SHAZAM (1993), SHAZAM Econometrics Computer Program, User's Reference Mamual, Version 7.0, McGraw-Hill, New York.

White, K. J. (1992), "The Durbin-Watson Test for Autocorrelation in Nonlinear Models", Review of Economics and Statistics, 74, 370-373. 
Table 1

Maximum Likelihood Estimation Results

\begin{tabular}{llllll}
\hline \multicolumn{1}{c}{$\boldsymbol{c}$} & $\mathbf{b}_{\mathrm{P}}$ & $\mathbf{b}_{\mathrm{I}}$ & $\mathbf{b}_{\mathrm{C}}$ & $\mathbf{b} \boldsymbol{\theta}$ & $\boldsymbol{\gamma}$ \\
\hline 1.2665 & 3.2559 & 1.6775 & 0.5511 & -3.0555 & 0.1114 \\
(n.a.) & $(7.661)$ & (n.a.) & $(0.222)$ & $(-1.658)$ & $(1.842)$ \\
$\mathbf{R}^{2}=0.478 ; \mathbf{G O F}=5.091$ (p-value $\left.=0.024\right) ; \mathbf{D W}=1.494(\mathrm{p}$-value $=0.036)$ & \\
\hline
\end{tabular}


Table 2

Some Basic Policy Simulations for (H/GDP)

\begin{tabular}{|c|c|c|c|c|c|c|c|c|}
\hline \multirow[t]{3}{*}{ Year } & \multirow{3}{*}{$\begin{array}{l}\text { (T/GDP) } \\
\text { (\%) }\end{array}$} & \multicolumn{7}{|c|}{ (H/GDP) } \\
\hline & & \multirow{2}{*}{$\begin{array}{l}\text { Actual } \\
(\%)\end{array}$} & \multirow{2}{*}{$\begin{array}{l}\text { Control } \\
\qquad \begin{array}{l}\text { (\%) }\end{array}\end{array}$} & \multicolumn{5}{|c|}{ Policy } \\
\hline & & & & $\begin{array}{l}1 \\
(\%)\end{array}$ & $\begin{array}{l}2 \\
(\%)\end{array}$ & $\begin{array}{l}3 \\
\text { (\%) }\end{array}$ & $\begin{array}{l}4 \\
(\%)\end{array}$ & $\begin{array}{l}5 \\
(\%)\end{array}$ \\
\hline 1969 & 23.64 & 7.77 & 7.75 & 7.26 & 6.54 & 6.15 & 5.95 & 5.65 \\
\hline 1970 & 23.86 & 6.95 & 7.53 & 7.17 & 6.47 & 6.07 & 5.92 & 5.63 \\
\hline 1971 & 25.69 & 6.95 & 7.65 & 7.23 & 6.45 & 6.01 & 5.84 & 5.52 \\
\hline 1972 & 25.73 & 7.60 & 7.97 & 7.39 & 6.63 & 6.20 & 5.97 & 5.65 \\
\hline 1973 & 25.29 & 8.29 & 8.30 & 7.67 & 6.93 & 6.51 & 6.26 & 5.95 \\
\hline 1974 & 27.00 & 8.98 & 8.50 & 7.68 & 6.95 & 6.51 & 6.19 & 5.89 \\
\hline 1975 & 29.33 & 8.31 & 8.71 & 7.52 & 6.81 & 6.38 & 5.92 & 5.63 \\
\hline 1976 & 28.12 & 9.71 & 8.36 & 7.29 & 6.55 & 6.13 & 5.71 & 5.41 \\
\hline 1977 & 28.08 & 8.36 & 8.17 & 7.02 & 6.32 & 5.90 & 5.46 & 5.17 \\
\hline 1978 & 30.90 & 8.47 & 8.86 & 7.35 & 6.59 & 6.13 & 5.57 & 5.26 \\
\hline 1979 & 29.42 & 8.04 & 9.25 & 7.87 & 7.08 & 6.64 & 6.11 & 5.80 \\
\hline 1980 & 30.41 & 9.24 & 9.17 & 7.79 & 6.99 & 6.52 & 6.00 & 5.68 \\
\hline 1981 & 30.56 & 8.80 & 9.61 & 8.03 & 7.25 & 6.78 & 6.19 & 5.88 \\
\hline 1982 & 31.40 & 8.52 & 9.73 & 8.14 & 7.28 & 6.78 & 6.20 & 5.86 \\
\hline 1983 & 31.05 & 10.03 & 9.31 & 7.80 & 6.95 & 6.45 & 5.89 & 5.55 \\
\hline 1984 & 28.99 & 10.01 & 9.62 & 8.36 & 7.51 & 7.02 & 6.55 & 6.21 \\
\hline 1985 & 28.70 & 9.37 & 8.75 & 7.71 & 6.83 & 6.33 & 5.93 & 5.58 \\
\hline 1986 & 29.85 & 9.23 & 9.13 & 7.74 & 6.95 & 6.47 & 5.95 & 5.64 \\
\hline 1987 & 30.56 & 11.27 & 9.28 & 7.99 & 7.07 & 6.54 & 6.06 & 5.69 \\
\hline 1988 & 33.88 & 9.81 & 9.30 & 8.53 & 7.17 & 6.43 & 6.15 & 5.62 \\
\hline 1989 & 33.43 & 9.47 & 9.51 & 8.54 & 7.28 & 6.60 & 6.25 & 5.76 \\
\hline 1990 & 36.08 & 9.09 & 9.51 & 8.71 & 7.27 & 6.51 & 6.22 & 5.68 \\
\hline 1991 & 35.84 & 8.89 & 9.53 & 8.64 & 7.15 & 6.38 & 6.06 & 5.49 \\
\hline 1992 & 33.68 & 8.73 & 9.54 & 8.93 & 7.47 & 6.69 & 6.47 & 5.91 \\
\hline 1993 & 34.22 & 9.56 & 9.84 & 9.27 & 7.78 & 6.98 & 6.77 & 6.20 \\
\hline 1994 & 34.53 & 11.30 & 9.98 & 9.37 & 7.92 & 7.13 & 6.90 & 6.35 \\
\hline Mean & 30.01 & 8.95 & 8.96 & 7.96 & 7.01 & 6.47 & 6.10 & 5.72 \\
\hline
\end{tabular}


Taxes and the Hidden Economy

Table 3

Policy Simulations for (H/GDP) (No Change to Tax Mix)

\begin{tabular}{|c|c|c|c|c|c|c|c|c|c|c|c|}
\hline \multicolumn{5}{|c|}{ Year Control } & \multicolumn{7}{|c|}{ Reduction in (T/GDP) } \\
\hline & & $10 \%$ & $20 \%$ & $30 \%$ & $40 \%$ & $50 \%$ & $60 \%$ & $70 \%$ & $80 \%$ & $90 \%$ & $100 \%$ \\
\hline & $(\%)$ & $(\%)$ & $(\%)$ & $(\%)$ & $(\%)$ & $(\%)$ & $(\%)$ & $(\%)$ & $(\%)$ & $(\%)$ & $(\%)$ \\
\hline 1969 & 7.75 & 7.40 & 7.07 & 6.75 & 6.45 & 6.15 & 5.88 & 5.61 & 5.36 & 5.12 & 4.89 \\
\hline 1970 & 7.53 & 7.21 & 6.91 & 6.62 & 6.34 & 6.07 & 5.82 & 5.57 & 5.34 & 5.11 & 4.90 \\
\hline 1971 & 7.65 & 7.29 & 6.95 & 6.62 & 6.31 & 6.01 & 5.73 & 5.46 & 5.20 & 4.96 & 4.72 \\
\hline 1972 & 7.97 & 7.58 & 7.21 & 6.85 & 6.52 & 6.20 & 5.89 & 5.60 & 5.33 & 5.07 & 4.82 \\
\hline 1973 & 8.30 & 7.90 & 7.53 & 7.17 & 6.83 & 6.51 & 6.20 & 5.91 & 5.64 & 5.37 & 5.12 \\
\hline 1974 & 8.50 & 8.06 & 7.64 & 7.25 & 6.87 & 6.51 & 6.18 & 5.86 & 5.56 & 5.27 & 5.00 \\
\hline 1975 & 8.71 & 8.19 & 7.69 & 7.23 & 6.79 & 6.38 & 5.99 & 5.62 & 5.28 & 4.96 & 4.65 \\
\hline 1976 & 8.36 & 7.86 & 7.39 & 6.94 & 6.52 & 6.13 & 5.75 & 5.40 & 5.07 & 4.76 & 4.46 \\
\hline 1977 & 8.17 & 7.66 & 7.18 & 6.73 & 6.31 & 5.90 & 5.53 & 5.17 & 4.84 & 4.52 & 4.22 \\
\hline 1978 & 8.86 & 8.24 & 7.66 & 7.12 & 6.61 & 6.13 & 5.68 & 5.27 & 4.88 & 4.52 & 4.18 \\
\hline 1979 & 9.25 & 8.66 & 8.10 & 7.58 & 7.09 & 6.64 & 6.21 & 5.81 & 5.43 & 5.08 & 4.75 \\
\hline 1980 & 9.17 & 8.57 & 8.01 & 7.48 & 6.98 & 6.52 & 6.08 & 5.68 & 5.30 & 4.94 & 4.61 \\
\hline 1981 & 9.61 & 8.96 & 8.36 & 7.80 & 7.27 & 6.78 & 6.32 & 5.89 & 5.49 & 5.12 & 4.77 \\
\hline 1982 & 9.73 & 9.05 & 8.43 & 7.84 & 7.29 & 6.78 & 6.31 & 5.86 & 5.45 & 5.07 & 4.71 \\
\hline 1983 & 9.31 & 8.65 & 8.05 & 7.48 & 6.94 & 6.45 & 5.98 & 5.55 & 5.15 & 4.77 & 4.42 \\
\hline 1984 & 9.62 & 9.03 & 8.48 & 7.96 & 7.48 & 7.02 & 6.59 & 6.19 & 5.82 & 5.47 & 5.15 \\
\hline 1985 & 8.75 & 8.21 & 7.70 & 7.21 & 6.76 & 6.33 & 5.93 & 5.55 & 5.20 & 4.86 & 4.55 \\
\hline 1986 & 9.13 & 8.53 & 7.96 & 7.43 & 6.94 & 6.47 & 6.04 & 5.63 & 5.25 & 4.90 & 4.56 \\
\hline 1987 & 9.28 & 8.66 & 8.08 & 7.53 & 7.02 & 6.54 & 6.09 & 5.67 & 5.28 & 4.92 & 4.58 \\
\hline 1988 & 9.30 & 8.64 & 8.03 & 7.46 & 6.92 & 6.43 & 5.96 & 5.53 & 5.12 & 4.75 & 4.40 \\
\hline 1989 & 9.51 & 8.85 & 8.23 & 7.65 & 7.11 & 6.60 & 6.13 & 5.69 & 5.28 & 4.90 & 4.55 \\
\hline 1990 & 9.51 & 8.82 & 8.18 & 7.59 & 7.03 & 6.51 & 6.03 & 5.58 & 5.16 & 4.77 & 4.41 \\
\hline 1991 & 9.53 & 8.81 & 8.13 & 7.50 & 6.92 & 6.38 & 5.87 & 5.40 & 4.97 & 4.56 & 4.19 \\
\hline 1992 & 9.54 & 8.89 & 8.28 & 7.72 & 7.19 & 6.69 & 6.23 & 5.80 & 5.40 & 5.03 & 4.68 \\
\hline 1993 & 9.84 & 9.19 & 8.58 & 8.01 & 7.48 & 6.98 & 6.51 & 6.08 & 5.68 & 5.30 & 4.95 \\
\hline 1994 & 9.98 & 9.33 & 8.72 & 8.15 & 7.62 & 7.13 & 6.66 & 6.23 & 5.83 & 5.45 & 5.10 \\
\hline Mean & n 8.95 & 8.40 & 7.87 & 7.37 & 6.91 & 6.47 & 6.06 & 5.68 & 5.32 & 4.98 & 4.67 \\
\hline
\end{tabular}


Table 4

Policy Simulations for (H/GDP) (Tax Mix Altered by Interchanging Personal and Indirect Taxes)

\begin{tabular}{|c|c|c|c|c|c|c|c|c|c|c|c|}
\hline \multicolumn{5}{|c|}{ Year Control } & \multicolumn{7}{|c|}{ Reduction in (T/GDP) } \\
\hline & & $10 \%$ & $20 \%$ & $30 \%$ & $40 \%$ & $50 \%$ & $60 \%$ & $70 \%$ & $80 \%$ & $90 \%$ & $100 \%$ \\
\hline & $(\%)$ & $(\%)$ & $(\%)$ & $(\%)$ & $(\%)$ & $(\%)$ & $(\%)$ & $(\%)$ & $(\%)$ & $(\%)$ & $(\%)$ \\
\hline 1969 & 7.75 & 6.97 & 6.70 & 6.44 & 6.19 & 5.95 & 5.72 & 5.50 & 5.29 & 5.09 & 4.89 \\
\hline 1970 & 7.53 & 6.90 & 6.64 & 6.39 & 6.15 & 5.92 & 5.70 & 5.49 & 5.29 & 5.09 & 4.90 \\
\hline 1971 & 7.65 & 6.93 & 6.64 & 6.36 & 6.10 & 5.84 & 5.60 & 5.37 & 5.14 & 4.93 & 4.72 \\
\hline 1972 & 7.97 & 7.08 & 6.78 & 6.50 & 6.23 & 5.97 & 5.72 & 5.48 & 5.25 & 5.03 & 4.82 \\
\hline 1973 & 8.30 & 7.36 & 7.07 & 6.79 & 6.52 & 6.26 & 6.01 & 5.78 & 5.55 & 5.33 & 5.12 \\
\hline 1974 & 8.50 & 7.36 & 7.05 & 6.75 & 6.46 & 6.19 & 5.93 & 5.68 & 5.45 & 5.22 & 5.00 \\
\hline 1975 & 8.71 & 7.17 & 6.83 & 6.51 & 6.21 & 5.92 & 5.64 & 5.38 & 5.12 & 4.88 & 4.65 \\
\hline 1976 & 8.36 & 6.94 & 6.61 & 6.30 & 6.00 & 5.71 & 5.44 & 5.18 & 4.93 & 4.69 & 4.46 \\
\hline 1977 & 8.17 & 6.68 & 6.35 & 6.04 & 5.74 & 5.46 & 5.19 & 4.93 & 4.68 & 4.45 & 4.22 \\
\hline 1978 & 8.86 & 6.96 & 6.58 & 6.23 & 5.89 & 5.57 & 5.26 & 4.97 & 4.69 & 4.43 & 4.18 \\
\hline 1979 & 9.25 & 7.48 & 7.11 & 6.76 & 6.43 & 6.11 & 5.81 & 5.53 & 5.26 & 5.00 & 4.75 \\
\hline 1980 & 9.17 & 7.39 & 7.02 & 6.66 & 6.32 & 6.00 & 5.69 & 5.40 & 5.12 & 4.86 & 4.61 \\
\hline 1981 & 9.61 & 7.63 & 7.24 & 6.87 & 6.52 & 6.19 & 5.88 & 5.58 & 5.29 & 5.03 & 4.77 \\
\hline 1982 & 9.73 & 7.71 & 7.30 & 6.91 & 6.54 & 6.20 & 5.87 & 5.55 & 5.26 & 4.98 & 4.71 \\
\hline 1983 & 9.31 & 7.38 & 6.98 & 6.60 & 6.23 & 5.89 & 5.56 & 5.26 & 4.96 & 4.69 & 4.42 \\
\hline 1984 & 9.62 & 7.96 & 7.58 & 7.22 & 6.87 & 6.55 & 6.24 & 5.94 & 5.66 & 5.40 & 5.15 \\
\hline 1985 & 8.75 & 7.32 & 6.95 & 6.59 & 6.25 & 5.93 & 5.63 & 5.34 & 5.06 & 4.80 & 4.55 \\
\hline 1986 & 9.13 & 7.35 & 6.97 & 6.61 & 6.27 & 5.95 & 5.64 & 5.35 & 5.08 & 4.81 & 4.56 \\
\hline 1987 & 9.28 & 7.56 & 7.16 & 6.77 & 6.40 & 6.06 & 5.73 & 5.42 & 5.12 & 4.84 & 4.58 \\
\hline 1988 & 9.30 & 8.00 & 7.49 & 7.02 & 6.57 & 6.15 & 5.75 & 5.38 & 5.03 & 4.70 & 4.40 \\
\hline 1989 & 9.51 & 8.03 & 7.54 & 7.08 & 6.65 & 6.25 & 5.86 & 5.50 & 5.16 & 4.85 & 4.55 \\
\hline 1990 & 9.51 & 8.15 & 7.62 & 7.13 & 6.66 & 6.22 & 5.81 & 5.43 & 5.07 & 4.73 & 4.41 \\
\hline 1991 & 9.53 & 8.06 & 7.51 & 6.99 & 6.51 & 6.06 & 5.63 & 5.24 & 4.86 & 4.52 & 4.19 \\
\hline 1992 & 9.54 & 8.38 & 7.85 & 7.36 & 6.90 & 6.47 & 6.07 & 5.68 & 5.33 & 4.99 & 4.68 \\
\hline 1993 & 9.84 & 8.70 & 8.17 & 7.68 & 7.21 & 6.77 & 6.36 & 5.97 & 5.61 & 5.27 & 4.95 \\
\hline 1994 & 9.98 & 8.81 & 8.29 & 7.80 & 7.34 & 6.90 & 6.49 & 6.11 & 5.75 & 5.42 & 5.10 \\
\hline Mean & 8.95 & 7.55 & 7.16 & 6.78 & 6.43 & 6.10 & 5.78 & 5.48 & 5.19 & 4.92 & 4.67 \\
\hline
\end{tabular}


Table 5

Policy Simulations for (H/GDP)

Effects of No GST

\begin{tabular}{llllc}
\hline Year & (GST/T) & Control & No Recovery & $\begin{array}{c}\text { GST Recovered With } \\
\text { TP and TC }\end{array}$ \\
& & & & $\mathbf{( \% )}$ \\
& $\mathbf{( \% )}$ & $\mathbf{( \% )}$ & $\mathbf{( \% )}$ & \\
& & & & 9.51 \\
1987 & 7.06 & 9.28 & 8.99 & 9.87 \\
1988 & 17.74 & 9.30 & 8.48 & 10.19 \\
1989 & 19.21 & 9.51 & 8.64 & 10.23 \\
1990 & 21.80 & 9.51 & 8.43 & 10.44 \\
1991 & 23.73 & 9.53 & 8.35 & 10.38 \\
1992 & 25.28 & 9.54 & 8.41 & 10.67 \\
1993 & 25.30 & 9.84 & 8.70 & 10.72 \\
1994 & 24.46 & 9.98 & 8.86 & $\mathbf{1 0 . 2 5}$ \\
& & & & \\
\hline
\end{tabular}

Table 6

Effect on the Tax Mix of No GST and No Recovery of Revenue

\begin{tabular}{|c|c|c|c|c|}
\hline \multirow[t]{2}{*}{ Year } & \multicolumn{4}{|c|}{ Actual (No GST) } \\
\hline & $\begin{array}{l}\text { Personal } \\
(\%)\end{array}$ & $\begin{array}{l}\text { Indirect } \\
(\%)\end{array}$ & $\begin{array}{l}\text { Company } \\
(\%)\end{array}$ & $\begin{array}{l}\text { Other } \\
(\%)\end{array}$ \\
\hline 1987 & $62.65 \quad(67.41)$ & $28.02 \quad(22.55)$ & $(9.43)$ & $0.57(0.61)$ \\
\hline 1988 & $52.94 \quad(64.35)$ & $35.34 \quad(21.40)$ & $11.17(13.58)$ & $0.56(0.68)$ \\
\hline 1989 & $56.26 \quad(69.63)$ & $35.54 \quad(17.74)$ & $9.25 \quad(11.45)$ & $0.95(1.18)$ \\
\hline 1990 & $51.35 \quad(65.67)$ & $34.38 \quad(16.09)$ & $12.93(16.53)$ & $1.34(1.71)$ \\
\hline 1991 & $53.99 \quad(70.79)$ & $35.32(15.20)$ & $9.72 \quad(12.74)$ & $0.97(1.27)$ \\
\hline 1992 & $51.70 \quad(69.19)$ & $37.64 \quad(16.55)$ & $10.30 \quad(13.78)$ & $0.35(0.48)$ \\
\hline 1993 & $50.70 \quad(67.87)$ & $37.66(16.55)$ & 11.31 & $0.33(0.44)$ \\
\hline 1994 & $50.08 \quad(66.29)$ & $36.24 \quad(15.59)$ & $13.56(17.95)$ & $0.12(0.16)$ \\
\hline Mean & $53.71 \quad(67.65)$ & $34.77 \quad(17.71)$ & 10.88 & $0.65(0.81)$ \\
\hline
\end{tabular}


Table 7

Incremental \% Reductions in (H/GDP)

For $10 \%$ Increments in (T/GDP)

(Based on Table 4)

\begin{tabular}{|c|c|c|c|c|c|c|c|c|c|c|}
\hline \multicolumn{4}{|c|}{ Year (T/GDP) } & \multicolumn{7}{|c|}{ Total Reduction in (T/GDP) } \\
\hline & $10 \%$ & $20 \%$ & $30 \%$ & $40 \%$ & $50 \%$ & $60 \%$ & $70 \%$ & $80 \%$ & $90 \%$ & $100 \%$ \\
\hline \multirow[b]{2}{*}{$(\%)$} & \multicolumn{10}{|c|}{ Reduction in (H/GDP) } \\
\hline & $(\%)$ & $(\%)$ & $(\%)$ & $(\%)$ & $(\%)$ & $(\%)$ & $(\%)$ & $(\%)$ & $(\%)$ & $(\%)$ \\
\hline 197023.86 & 8.37 & 3.77 & 3.77 & 3.76 & 3.74 & 3.72 & 3.68 & 3.64 & 3.78 & 3.73 \\
\hline 197529.33 & 17.68 & 4.74 & 4.69 & 4.61 & 4.67 & 4.73 & 4.61 & 4.83 & 4.69 & 4.71 \\
\hline 198030.41 & 19.41 & 5.01 & 5.13 & 5.10 & 5.06 & 5.17 & 5.10 & 5.19 & 5.08 & 5.14 \\
\hline 198528.70 & 16.34 & 5.05 & 5.18 & 5.16 & 5.12 & 5.06 & 5.15 & 5.24 & 5.14 & 5.21 \\
\hline 199036.08 & 14.30 & 6.50 & 6.43 & 6.59 & 6.61 & 6.59 & 6.54 & 6.63 & 6.71 & 6.77 \\
\hline 199434.53 & 11.72 & 5.90 & 5.91 & 5.90 & 5.99 & 5.94 & 5.86 & 5.89 & 5.74 & 5.90 \\
\hline $\begin{array}{l}\text { Mean 30.01 } \\
(1968-1994)\end{array}$ & 15.64 & 5.17 & 5.31 & 5.16 & 5.13 & 5.25 & 5.19 & 5.29 & 5.20 & 5.08 \\
\hline
\end{tabular}

